\title{
Ubhauli and Udhuali: Application of Symbolic Ecology and Ecological Symbolism in Kirat-Rai in Eastern Nepal
}

\author{
Dr. Bishnu Prasad Dahal*
}

\begin{abstract}
The aim of this article is to explore how the Ubhauli and Udhauli are functioning as a mechanism to maintain the socio-cultural and economic-ecological balance between populations and resources with the help of symbolic and ecological perspectives These great and holy festivals of KiratRais through which they can understand symbolic ecology and ecological symbolism in Kirat world through which Kirat can easily understand the nature, ecology and culture for their adaptation. Ubhauli and Udhauli festivals offer the social harmony, solidarity, integration through the socialization and such entertainment; works as mechanism of conflict resolution in socio-cultural, religious, ecological, economically, linguistically etc. to cope with the existing environmental, cultural and social problems of the Kirat world. The festivals Ubhauli and Udhauli are celebrated twice in a year. April and November are the celebrating months which appear through seasonal changes that help to bring society in order through repetitions and re-beginnings.
\end{abstract}

Key words; Ubhauli, Udhauli, symbolic ecology, ecological symbolism, Kirat, etc.

\section{Introduction}

Festivals like Ubhauli and Udhauli have great significance in the Kirat world. Manifestly, these festivals stand as festivals of Kirat ideologies, ideals and entertainment but latently these festivals function as the mechanism of socialization, adaptation with environment, reciprocity of populations with resources, and these festivals have great significance with ecology too. That's why the aim of this research is to explore the reciprocal relationship between the ecological factors with cultural in Kirat world. Here I want to transplant the theoretical standpoint of synthesis concepts of symbolism with ecological perspectives propounded by various ecological anthropologists and anthropologists like Steward, Rappaport, Harris, Vayda, etc. to crystallize the theoretical concepts to understand the interplay between Kirat people, their cattle and their surroundings.

\subsection{Culture and ecological balance}

This article aims to identify how environmental phenomena are responsible for the development of culture of human population migration and cattle movement. This article

*Dr. Dahal is an Assistant Professor of Anthropology, Patan Multiple Campus, TU, Nepal 
also tries to demonstrate the effect of ecological constraints on Kirat's economic life, due to harsh ecological condition and limited resources- fertile soil/land grazing land, forest products. So, the Kiratemployed herding, agriculture and other domestic small- scale cottage industries as economic strategies including migration as Gorkha soldiers in British and Indian regiments and were forced to live at a bare subsistence level. When winter comes they migrate towards the low altitude valley of Arun along with their cattle for protection from the cold as well as to manage the scarce resources. When summer comes they move reverse along with their livestock. In this way, cultural ecological study of that society recognized or indicated that environment and culture (all spheres of life) are not separate spheres but is involved in "dialectical interplay" or "reciprocal causality" (Bohannan, \& Glazer, 1988). So, it is clearly observed that there is a cause and effect relationship between "economic strategies" and "ecological constraints or conditioning" as one influences the other that found in Kirat world (Molnar, 1981).

Here I want to propose not only to emphasize the factors that are material and play key role to determine the culture as Julian Steward has done, but it is better to complement the Stewardian model by synthesizing the system model propounded by Andrew Vayda and Roy Rappaport so as to better understand the practice of Ubhauli and Udhauli festivals of Kirats of east Nepal. That's why it is better to transplant the theoretical concepts ofVayda and Rappaport's paradigm of human ecology including population as a unit of analysis"ecosystem or ecology as the context and adaptation as the dynamic process of interaction between population and ecosystem."

In my opinion, among all theoretical standpoint, system based analysis is more appropriate to understand the interplay between human behavior i.e. culture with environmental resources; and this model provides a clear- cut framework for analysis of human interactions with the environment. The main feature of this model is the basis for making a holistic description of Kirat world with their interactions with ecosystem. Such a total description would be as useless as it would be undoable in other cases but in case of Kirat world some socio-cultural phenomena and their significance should be understood in relations with ecological and ecosystem perspectives to understand the Kirat as a human, Ubhauli and Udhauli as a culture and existing resources availability, management, outsources etc as livelihood practices to exist the all these cultural practices in given the immense complexity of even the simplest social and ecological systems.

For this it is better to analyze the energy input in the model of subsistence or technology and social institutions of work to collect and produce food. All of this was set within the biological framework of limiting factors and carrying capacity. Similarly, components of culture such as socio-religious or cultural ceremony, festivals, occasions are also playing 
key role that helped to maintain a balance between populations (human and non- human) and its resources. Socio-cultural occasions and ceremonies as regulating the delicate balance between human and non-human population and to reduce competitions between these species could be compared with the study of Vayda and Rappaport. It is observed that humans and non-humans are surprisingly close in physiology, body and group size and in the omnivorous diet pattern suggesting the similar way of exploiting (modes and means) natural resources (Bohannan, \& Glazer, 1988).

In anthropology, dialectical approach is widely used to study the inter relationship between the specific culture, nature (environment), technology and human behavior. Marvin Harris is one of the anthropologists or theorists who synthesized the three scientific approaches: Marxists' historical materialism, cultural ecology, and neo-evolutionism to understand the interrelationship (may be sometimes reciprocal, causal or non reciprocal) in which the substructure or infrastructure (technology, economics, demographics), structure (cultural and kinship systems), and superstructure (ideology, religion) but regards culture more as evolutionary than determined, with infrastructure, especially reproduction, operating as the primary variable in determining cultural development (Harris, 1968). New cultural characters or cultural development happens when the changes in the infrastructures ultimately influence to the structures and then superstructures but in few cases the changes in the infrastructure and changes in the structures do not always determine the changes in the superstructures. In the case of Kirat-Rais in the Diaspora world are not changing attitudes cultural norms and values (superstructure) though there are widely changes in components of culture (infrastructure) and the agents who can help to perform such cultural function and activities (structure) of their society and culture.

\subsection{Kirat Festivals and Cultural Symbolism}

Festivals can be categorized into various types according to the significance in society and culture such as national, religious, and seasonal. The main functions of the cultural festivals are to engage people in socio-cultural performance to make people happy intheir lives, and to maintain the social order within their complexities and it helps to strengthen the sense of solidarity, commonality, harmony, and sense of humor.

In eastern Nepal, all people celebrate the Ubhauli on Baishak Sukla Purnima or same day of Bhuddha Purnima and Sakela Ubhauli falls on the month of Baishak (April-May) among them mostly, Kirat- Rai community is one who celebrate this festival in reference to adapt in the changes in the climatic conditions, lack of environmental resources to survive the population in their niche. In Nepali word Ubhauli and Udhauli means- 'Ubho - going up' and 'Udho - going down'. Ubhauli and Ubhauli are those festivals which have great significance in Rai community to cope the harsh situation of disequilibrium between 
available population with resources while the resources cannot extent in some limit in one way and population cannot reduce suddenly, while, Sakela Udhauli falls during then moth of Mangsir (October-November) of Bikram Sambat calendar. The Kirati are the inhabitants of the eastern hilly regions - Bhojpur, Khotang, Dharan and Dhankuta. They are agriculturist and they are the worshipper of nature.

Indigenous knowledge system of the Kirat people is found more scientific and they used to climb up to the hilly region in summer to avoid the raising temperature and to protect from the malaria (epidemic). Manifestly, they perform the festival Ubhauli and Udhauli for religious purpose but latently it is the appropriate strategy to cope the uncomfortable situation of disequilibrium conditions of human, non human population in relation with environmental resources. Usually, they knowing and unknowingly accept that these traditional rituals they worship their ancestors and nature, seeking better, health, wealth and crops. At the start of winter with similar rituals for Udhauli they used to move down the hill and when summer starts, they move downward to cope unwanted crisis of resources and their adaptation. They have good knowledge about the regeneration of resources in relation with outflow of population from the defined niche.

This research article aims to explore the interrelationship between ritual (Ubhauli and Udhauli) and resources (ecology) with the help of symbolic or interpretative perspective to understand how religious festivals help to maintain the equilibrium relationship with resources in changing climate. That's why; here I like to define the symbolic ecology to understand situation and adaptive situation of Kirat through the holy rituals- Ubhauli and Udhauli in eastern Nepal. "Symbolic ecology of Kirat" of eastern Nepal also known as "ethnoecology of Kirat" tries to assess the cultural system as a symbolic system that produced social, religious, cultural, political and economic shared norms, values and webs of significance and communication (Geertz 1973), but also practical effects on the level of social organization (Turner 1967). Here I would like fuse the Geertzian ideas of "indigenous knowledge system", with the "system based approach" or ethnosemantic taxonomies" of Roy Rappaport (1984), and "structural hierarchy" or "systems of classification" propounded by Lévi-Strauss to redesign the new perspective in "ecological anthropology" which mainly studies the cultural changes and adaptation is mainly the reciprocal relationship between and among the biotic and abiotic components of the particular ecosystem and socio-natural settings and the study should be scientific, through the depth study of their artifacts within the system. So, "symbolic ecology" is only the appropriate theory to study the interrelationship between and among the ecological, cultural, social, political and technological components through the holistic and integrated approach to emphasis on the socio-cultural construction of "nature", recognizing that 
"conceptualizations of the environment are the products of ever-changing historical contexts and cultural specificities” (Descola and Pálsson 1996).

\section{Theoretical Overview}

The human population with livestock movements is one of the best adaptive strategies of the Himalayan herders. When the snowfall begins, the grassland is affected and to cope with this environmental conditioning, the herders usually move their livestock to the area with grass availability.

Ecological anthropology as the discipline is to examine human and non human population's adaptation which is associated with the various material and non-material components of the culture to socio-natural environment. Marvin Harris is one of the anthropologists who apply materialist approach to understand the reciprocal relationship between culture and environment, based on biological and psychological constants of human nature. Harris's theory believe that each society deals with problems of production - "behaviorally satisfying minimal requirements for subsistence,"(Harris, 1979) which is known as etic behavioral mode of production and similarly, the society tries to solve their basic and minimum requirements of production for subsistence and for such production reproduction is essential and they are reciprocally interrelated and determined with each other. That's why if reference to Malthus human reproduction is directly proportionate with production and the issue of reproduction of humans determined by the mode, means and relationships of production to create equilibrium conditions that balance the increase and decrease of the population, i.e. behavioral mode of reproductionor etic behavioral domestic economies and etic behavioral political economies (Harris, 1979). Lastly, the speech acts, values, norms, attitudes and symbolic dimensions (psychic unity that plays a significant role in people's consciousness) lead to productive behavior in terms of ethics, art, sports, etc. i.e.behavioral superstructure.

Here, according to Harris model, the change in sub-structure or infrastructure or changes in modes of production (change in technology of subsistence, changes in technoenvironmental relationships, changes in ecosystems, and work patterns) and changes in modes of reproduction (demography, mating patterns, fertility, etc.) leads to changes in structure or changes in domestic economy (family structure, domestic division of labor, socialization and education, sex roles, etc.) and changes in political economy (political organization, taxation, division of labor, class, hierarchy, control, war, etc.) is observed (Harris, 1979) which ultimately enforce to change in the behavioral superstructure of that particular society and culture like- art, music, dance, literature, rituals, sports, games, and science (Harris, 1979). But in case eastern Kirat-Rais, there is clear cut picture of changes in infrastructure and structure of the study area but there are no any changes in 
superstructure of people who live in that particular ecosystem, or away from that ecosystem and in Diaspora. That's why Harris theory is partly true for Kirat world to understand the interrelationship between and among the component of culture and component of environment.

After Harris, there is shifting scope to study the human population instead of culture with a sub discipline of ecological anthropology as- "new ecology" in which the unit of analysis changed from “culture” to "human populations” (Rappaport 1968). In Rappaport's Pigs for the ancestors (1968), human population, pig population, exchange patterns, nonliving substances, agricultural production and distribution of land were all interrelated in the Tsembaga Maring of New Guinea, as part of an ecosystem that regulated itself through a special mechanism of "negative feedback". Here cultural practices and beliefs were seen as the means for the maintenance of a homeostatic equilibrium.

After 1960s there is great debate between anthropologists in terms of modern concepts and divisions between "nature”, “culture”, and "society”. That's why "symbolic ecology" is one of the alternate perspectives to study their interrelationship through the synthetic approach between the symbolic and material approaches, however most of the early ethnographies did not account for such dimensions. So as the Geertzian "thick description" was criticized for not being "thick" enough (Roseberry 1989), and there is no systematic way of analysis of components ecology in "symbolic ecology" for not being "systemic" enough. In a sense, cultures" are contested and contented according to the time and context and they are inextricably tied to processes of social and cultural differentiation. This reference to differentiation, Roseberry claimed, "Is in part, reference to the connections between culture and relations of power and domination (Roseberry 1989) and it should be studied through thick description rather than thin one.

In the study of, interrelationship between cultural activities or religious ceremonies where most of the people are practicing the culture to balance of energy flow in their particular cultural ecology as interplay between "nature” and "society” as a cosmological objective in which nativeKirat-ecological concepts played a dominant role in the study area. Thus, ethno-ecological knowledge or indigenous knowledge system could not stand as the alternate concept to deal about the interplay between nature and society as a broader sense to explain the overall socio-natural problems including human and non human interactions with each other and the ecology through the culture. Instead, it became the casual outcome or something that could be simply assimilated through everyday experience which cannot explain the present situation of overall socio-natural settings in behaves of the changing cultural trends. So, it is the sub discipline of ecological anthropology which is a structural approach with disciplined knowledge based on a long tradition of enquiry and which is 
acquired of necessity as part of his intellectual equipment for biological and cultural survival” (Reichel-Dolmatoff, 1976).

Here, material culture and symbolic study are not different concepts while studying culture through thick description and these concepts are simultaneously meaningful and material. In the transition from "ecological" to "environmental" anthropology the debates around extraction, conservation and entitlements have been decisive. Here the attention is not so much centered on the interrelations between human groups and "their environment", but on the study of "environmentalism" as a set of discourses and practices (Little, 1999). However, in the analysis of how conceptions of environment and territory inflect particular forms of governance, Foucault's attention to the emergence of "power-knowledge technologies" has become a fertile ground for political ecology. How "nature" becomes "environment", how it is defined and categorized, and how environmental problems are represented and intervened constitutes, at least in part, a form of "environmental rule" or "green government" (Peet and Watts, 2011). In other words, it has become inextricably tied to the exercise of power over populations, their identities, and their territories in one way and in another way, state and state agencies including native socio-cultural organizations or agencies are now governed and controlled by the concepts of cultural representation by the ideologies of mal-participation, mal-identifications and mal-representation in agencies including socio-cultural and ecological according to their population, territories, identities.

Now, I am going to propose the new theoretical perspective which significantly elaborate the interrelationship between and among nature or ecology, culture, symbols and use of environmental resources and its sustainability for the development of culture and protection of environmental resources and that should scientifically study and follow the previous ecological anthropological trends and methodologies of Steward (1955), Roy Rappaport (1967), Vadya (1976), Marvin Harris (1968) complimented by the analytical methods of Geertz (1973) to elaborate the environmental ecological knowledge with the perspective of culture to wise use and sustain the resources for future generations through the preservation of culture as well i.e. protection and preservation of environment and culture or sustainability. The symbolic-ecological anthropology tries to gives a new approach to deal about the interplay between culture and ecology with new dimension. Currently, it has not much focused on either adaptation or, reproduction but, giving attention to both the biological , social, cultural, ecological, economic, climatic, religious etcfactors, and the full range of human factors in the environmental resource direction, environmental changes, climate changes and cultural crisis, and looking how to cope and how to adapt in new changing environmental condition and cultural context to save environment, culture and humanity for sustainability, and save humanity. 
In another way ecological symbolism refers to the study of symbolic meaning within the human environment including personal, social, cultural, and mythic contexts of understanding the socio-natural system. In the "broadest possible view" (Martin and Guerin, 2005) ecological symbolism has attempted to give a holistic definition of both the artificially created and situation after human activities built and natural environment as human space, "symbolism of the built environment" (Clark,2008) and "architectonic analysis” (Preziosi, 1979). In a way ecological symbolismdeals with ecological psychology to understand how space becomes a vessel of personal symbolic meaning in this regards, how Kirat Rai understand the Ubuali and Udhauli in their own socio-cultural-natural settings by using symbolic interpretation. So, the aim of this research paper is basically to identify the emic (indigenous) approach of Kirat-Rais to understand the ecological knowledge about the environment, nature, culture, and so on through the festivals of Ubhauli and Udhauli using symbolic perspectives.

After reviewed the overall theoretical strength of all ecological and symbolic ecological theories, it was found that the systems model is the best among all as the research framework, because this ecosystem based model can help the problems of Kirat- Rai world including the boundaries of the forest resources, land resources, available for optimum survival of the human population (Kirat-Rai) in that ecosystem, and this model only can provide the alternate livelihood strategies to live the human (Kirat) and non-human(cattle) population to provision of alternative sources of energy to that ecosystem where regeneration of resources through the migration is pre-dominantly practiced through the culture and they are well known about the resources-cultural-environmental well understanding scientifically. So, with the help of this research it is aimed to find out the real value of symbolic- ecology in Kirat society lies in helping humans to see previously unrecognized relationships between what people do and the environment in which they do it. This research tried to explore how people think about the world and their place within it, how they use their culture to adop in their particular environment.

\section{Methodology}

It is qualitative research in which participant observation, key informants interview, focus group discussion methods are used to gather the information. This research is based on the participant observation of Ubhauli and Udhaili, village headman, socio-cultural leaders; seniors who reside in Majha-Kirat of Eastern Nepal. The research is conducted by selecting purposive sampling among the Ubhauli and Udhauli festival participants who can explain the whole religious ritual or festival from historical, socio-cultural and naturalist perspective with significance among the Kirat-Rai in the study area. Data collection, methods, were conducted so as to identify the issues or research theme more scientific, fact, valid and 
reliable so as to elaborate, tojustify and to signify the importance of festivals of Ubhauli and Udhauli to identify the present the actual situation. Pseudo-name is used to maintain the research ethics and research area in psudonamed as - Naldhum. Naldhum is the area where KiratRai are predominantly inhabitants and Naldhum represents symbolically all socionatural settings of any places from eastern part of modern Nepal which covers Solukhumbu, Okhaldhunga, Khotang and Bhojpur.

\section{Ubhauli and Udhauli: Symbolic ecology to Ecological Symbolism}

The goals of symbolic ecology or ecological symbolism are to interpret or to open the socio-cultural events and phenomena into different meaning according to time, context and conditions. First of all, many anthropological classical schools and modern anthropological schools try to familiarize the readers with the particular culture while symbolic ecology or ecological symbolism tries to interpret the same culture into different situation with different meanings. Here, symbolic ecology or ecological symbolism of celebrating Ubhauli and Udhaulican be illustrated as

\subsection{Ubhauli and Udhauli: Festival of Nature}

Symbolic ecology and ecological symbolism are the alternative perspectives to analyze the socio-cultural human behavior in associations with natural components like climate, geography, topography, resources availability etc. in a wider sense. In ecosystem, ecology acts as a major component of variations; either genetic variation (either by geographical isolation, or by adaptation of species or by origin of new species) or cultural variations. In this context there is interplay between nature and nurture i.e. ecology, human biology vs culture in terms of studying of human behavior. Here, nature vs. nurture debate is one of the most common while studying the human behavior. "Nature" refers to overall ecological predispositions' impact on human traits, and "nurture" describes the influence of learning and other influences from one's environment.

From Kirat mythological points of view, this world is possible when Paruhang who lived in Heaven fell in love with the beautiful Sumnima, who live in earth got married and this world became possible. Paruhang abandoned Sumnina for lone time and one day all of sudden Paruhang came back and he tried to console Sumnima but she did not believe him. So in order to get truth from him Sumnima asked him to put on the Buti, and Sumnima through that buti found that Paruhang was looking at the heaven and earth from the top of Chomolongma (Mt. Everest). She also knew that he was meditating and visited entire universe, he then promised never to leave her again (Nocoletti, 2006). In this happiness Kirat Rai celebrates the festivals which are mostly in the worshiping nature in their own cultural calendar and they usually dance with joy and happiness to make harmonious 
relationship with nature through the culture. So, it greatly signifies that, symbolic ecology and ecological symbolisms are the appropriate to analyze the reciprocal relationship between Kirat Rai population, culture and the ecosystem in which they allexist.

\subsection{Ubhauli and Udhauli: Religious Significance}

The Kirat people are naturalist who worship nature, their ancestors and the universe. Most of the rituals, religions, festivals and celebrations are designed to worship them. Ubhauli is the festival in which they worship nature for a good harvest, while inUdhauli, Kirat Rai worship their ancestors and deities for their soul to keep in peace and happy including the cultural socialization with happiness, joy and entertainment. According to the Nepalese anthropologists, Kirat-Rai celebrate Sakela as a cultural performance that includes KiratRai's history, culture, civilization, identity and philosophy associated with Kirat civilization and culture. The Sakela dance is performed in various sillis (steps), which are an imitation of the ancestors' tasks they got from their ancestor. The Dancers of Sakelasilli in Ubhauli and Udhauli re-enact actions like what are doing in their farming, daily life and in nature like cutting the trees, ploughing the fields, sowing the seeds and harvesting the crops. Sakela is a group dance in which Kirat Rai admires their ancestor and their work i.e. work in land or say worship the nature twice a year because mostly in the land where Kirat predominantly inhabits there are twice cropping system per year. So, they express their gratitude to their ancestors by through their art of imitation. In festival Ubhauli Kirat Rai worship the land, nature and the universe for the protection of the crops from disasters and natural calamine.

\subsection{Ubhauli and Udhauli: Festival of Happiness}

The festival has great significance in Kirat world because it is unique festival among other ethnic and caste people among Nepal and the festival is celebrated to worship nature for good plantation and harvesting. During Ubhauli and Udhauli, there is ritual performed in which three stones are worshiped and they are considered as symbols of earth, the universe and ancestors and people worshiped all three in their rituals and Kirat Rai respect nature and the Ubhauli and Udhauli evoke the awareness to be honest towards the nature and their ancestors (Hatuwali,2008). In Such festivals, Sakela is mostly performed and alltogether people used to dance for five days in different places. Chula is the main symbol of the Kirati religion where the Rai people used to worship their ancestors and living souls. They use such gathering to establish the friendship (mit) or to choose their bride and groom as their need and necessity. That's why such festivals are highly signified for such religious, social, cultural purposes. It is believed in Kirat Rai world that, after worshipping the Sakawa and participating in the Sakelasili festival, in the coming year they will have a good 
harvest, good ways of income andthere would be prosperity in the family. So, Ubhauli and Udhauli have great significance in Kiratworld mentallyand physically

\subsection{Social Significance of Ubhauli and Udhauli}

Festival provides a platform to express, share and understand their ideas to others through interactions. The functions of festivals are imparting entertainment, socialization through participation, and festivals act as a mechanism to resolve the social tensions, conflicts, and social stress through participation of their members and it provides the societal glue and it offers people meaning and purpose for their lives, and it gives definite values.

In Kirat Rai world festivals like Ubhauli and Udhauli help to bring togetherness, harmony, integration and having we feeling among the members because the society is dynamic and the population of Kirat Rai world are more mobile. Some of them migrate to lowland temporarily; some go away from motherland to recruit in British and Indian Army. Such kinds of fragile society need a mechanism to reduce the tensions, angers, and stress within households and in community level. So, society needs interactions and Ubhauli and Udhauli acts as a mechanism to resolve these problems and Ubhauli and Udhauli functions as remedy or the solutions of such misunderstanding or disagreements. So, Ubhauli and Udhauli festival offers the opportunities for social, cultural, individual and familial interactions, those who are far from home often return to celebrate the festival to establish their social exchange among Kirat world. Its main social importance could be to build social exchange within the Rai community because in the Rai Kirati community there are 30 tribes which have different languages and identities although the Rais represent one community. Within Kirat Rai there are 30 clans or sub groups who are with distinct identities and languages and such festival offers as the meeting point for all to share their feelings and emotions in the name of such traditional culture.

\subsection{Ecological Significance of Ubhauli and Udhauli}

Ubhauli and Udhauli festival is considered as a most important festival in Kirat Rai world because in this festival people worship nature, worship to respect the ancestors and feel their own cultural identity to socialize the new generation through the rituals, dances, worshipping, and interactions. Nakcho (Dhami) ritually purify all instruments by chanting ritual oaths that are needed in Sakelasilli dance andthenUbhauli and Udhauli starts. First of all, all traditional instruments (except drums) are kept in tree leaves of chest nut plant (Katush) which is available in Kirat World locally in Naldhum. Besides these, Totola, ginger and yeast water (Marchapani) is needed forverdict and purification to all instruments that are used in festival (Shiwahang,2012). Totola banana's leaf and ginger is needed for Kachur and the result of verdict. These entire floras are essential in ritual function in 
Ubhauli and Udhauli. Kirat Rais need chicken as ritual fauna to sacrifice in Ubhauli and Udhauli. Then, Nakcho recall the Mudumi language that, "through yoursounds, you all are able to call a good harvest and we are always thankful towards you” and after worshiping to all traditional instruments, the Sakelasili festival willbe over. So, neither without worship nature, ancestors and instruments neither Ubhauli norUdhuali starts nor end. It is found from the observation and participation that Kirat-Rais mostly worship nature, land, ecology flora etc. and there is great significance of knowledge of environment correlation with culture and religion.

\subsection{Socio-cultural Significance of Ubhauli and Udhauli}

Kirat- Rai society must understand through the symbolic ecological or ecological symbolic perspective because all rituals festivals like Ubhauli and Udhauli have their own meaning and such symbols carry ecological, economic, climatic, adaptive, cultural, meaning to the people who are both Kirat-Rais and who are non Kirat- Rais. These ritual's symbolscarry meanings in a metaphorical way through which one can understand the lives of Kirat- Rai in Naldhum. Rituals are the texts which can be read for theirsymbolic significance (Howe, 2000). The uniqueness of these rituals is they deserve particular meaning for particular cultural items inparticular places, times and cultures and it has great significance in society to resolve socio-cultural, ecological, economic and religious problems by maintain social order in Kirat society.

\subsection{Significance of Ubhauli and Udhauli in Diaspora}

Kirat Rai celebrate the Ubhauli and Udhauli not only the places in Kirat origin, but they are celebrating these festivals in Kathmandu and Diaspora. How significant to celebrate these festivals in Diaspora? There are larger groups that they have migrated towards Kathmandu or in many places of the country, excepts these very large number of Kirat Rai are also migrated towards many cities of India, many cities of Britain and many cities of America for seeking job and opportunities. In this regard, Ubhauli and Udhauli are the rituals which stands as super structure of the Kirat world in Diaspora too but what are the structure that Kirat people develop in the Diaspora and what are the infrastructural elements of modes of production in Diaspora that help to keep Ubhauli and Udhauli at top level as Marvin Harris said. What keeps such super structure living alive till now though there is nothing to support structure and infrastructure for Ubhauli and Udhauli in Diaspora?

\section{Conclusion}

It is found that from my participant observation, Ubhauli and Udhauli festivals offer the social harmony, solidarity, integration through the socialization and such entertainment; works as mechanism of conflict resolution in socio-cultural, religious, ecological, 
economically, linguistically etc. to cope with the existing environmental, cultural and social problems of the Kirat world. Finally, whole festivals of Kirat-Rais in Nepal are not simple entity, they are complex whole through which participants (signifier) and observers (signified) the socio-cultural, political, religious, familial, emotional, recreational etc. messages (messages of solidarity, transactions, cohesion, harmony and integrity through socialization) they passes and observer perceive such messages through entertainment of festivities and various celebrations within and between diverse generations, caste, ethnicity, economy, ecology, family, kin or say society and culture in a greater term. Such festivals promote the members of the Kirat society andculture by offering fests, meals, prasad, blesses, wishes, sharing, feelings, emotions manifestly and they exchange love, affection, respects among all stakeholders of patri-kins to matri-kin's, communities, societies latently socialize to obey the norms, rules, regulations, values in behaves of the members of that society to maintain the relationship for the stability of their society in dynamic cultural world. From this research, it was found that with the help of ecosystem based model c is is very easy to understand the various problems of Kirat- Rai world like, nich, carrying capacity, dilectism in population and resources inter-play available land resources forest and others. I found that there is delicate balance of both human and non human population with resources and migration from Kirat world- downward displacement is for resources regeneration which is regulated by the cultural calendar through which Kirat life became very comfortable. From the ethno-ecological perspective, Ubhuali and Udhauli is creating the mechanism of maintaining harmonic order between population and resources which is found more rational and scientific than modern society.

\section{References}

Bohannan, P. \& Glazer, M. (ed) (1988). High Points in Anthropology. McGraw-Hill, Inc., New York

Clark, L. (2008). The Meaning of Threshold: A Preliminary Typological Study of the Symbolismof Entry. Paper presented atthe Interior Design Educators Council Midwest RegionalConference, Lincoln, Nebraska.

Descola P, and Pálsson G. (1996). Nature and Society, Anthropological Perspectives. London: Routledge.

Geertz, C. (1973). The Interpretation of Cultures. New York: Basic Books, Inc., Publishers.

Harris, M. (1979). Cultural Materialism: The Struggle for a Science of Culture.New York: Random House.

Hatuwali, (2008). Sakawa,[Text in Nepali],(Sakawa festival), Bantawa research center,Kathmandu. 
Howe, L. (2000). Risk, Ritual and performance. The Journal of the Royal Anthropological Institute, 6(1), 63-79, London; Royal Anthropological Institute of Great Britain and Ireland

Little, P. E. (1999). Environments and Environmentalisms in Anthropological Research: Facing a New Millennium. Annual Review of Anthropology, 28: 253-284.

Martin, C., \& Guerin, D. (2005). The Interior Design Profession's Body of Knowledge. Interior Design Educators Council and, University of Minnesota; Study Manual.

Nicoletti, M. (2006). The Ancestral Forest: Memory, Space and Ritual among the Kulunge Rai of Eastern Nepal. Kathmandu: Vajra Books.

Peet, R. and Watts, M. (2011). Global Political Ecology, New York: Routledge

Preziosi, D. (1979). Architecture, Language and Meaning: The Origins of the built World and its Semiotic Organization.TheHague: Mouton.

Rappaport, R. A. (1968). Pigs for the ancestors: ritual in the ecology of a New Guinea people. New Haven, Connecticut, USA: Yale University Press

Reichel-Dolmatoff, G. (1976). Cosmology as Ecological Analysis: A View from the Rain Forest. In: Man, New Series 11(3):307-318.

Roseberry, W. (1989.Anthropologies and Histories, Essays in Culture, History and Political Economy. London: Rutgers University Press.

Shiwahang J. (2012).KiratMundhumBhirrakoBigyan, [Text in Nepali],(Kirat scientificknowledge inside the Mudhum),NEFIN,Ekantakuna ,Lalitpur.

Steward, J. (1955). Theory of Culture Change: The Methodology of Multilinear Evolution. Urbana: University of Illinois Press.

Turner, V. (1967). The Forest of Symbols: Aspects of Ndembu Ritual. Ithaca, London: Cornell University Press.

Vayda, A P., and Rappaport, R. (1976). Ecology, Cultural-Noncultural, In Human Ecology, edited by P. Richerson and J. McEvoy North Scituate, Mass.: Duxbury

Molnar A. (1981). Economic Strategies and Ecological Constraints: Case of the Kham Magar of North West Nepal, in C. Von Furer- Hamimendorf (ed.), Asian Highland Societies: In Anthropological Perspective, New Delhi: Sterling Publishers Pvt. Ltd. PP.20-51.

Vayda, A.P., (1976). War in Ecological Perspective. New York: Plenum Press. 